\title{
A BNCC da Educação Infantil e suas contradições: regulação versus autonomia
}

\author{
BNCC of Childhood Education and its contradictions: \\ regulation versus autonomy
}

\author{
La BNCC de la Educación Infantil y sus contradicciones: \\ regulación versus autonomía
}

IVONE GARCIA BARBOSA*

Universidade Federal de Goiás, Goiânia- GO. Brasil

TELMA APARECIDA TELES MARTINS SILVEIRA**

Instituto Federal de Goiás, Anápolis- GO. Brasil.

MARCOS ANTÔNIO SOARES***

Universidade Federal de Goiás, Goiâni- GO. Brasil

\begin{abstract}
RESUMO: O presente artigo analisa a constituição da Base Nacional Comum Curricular (BNCC) no contexto político, social e econômico brasileiro e seus impactos no campo da Educação Infantil. Utilizando da dialética materialista como referência, por meio de análise documental, busca-se demarcar os princípios orientadores da BNCC, a qual se articula com uma concepção pragmática de educação vinculada ao modelo neoliberal. Enfatizam-se suas contradições e implicações para a Educação Infantil.
\end{abstract}

Palavras-chave: BNCC. Educação infantil. Políticas públicas educacionais.

* Doutora em Educação pela Universidade de São Paulo. Professora Associada IV da Faculdade de Educação da Universidade Federal de Goiás, onde atua no curso de Pedagogia e no Programa de Pós-graduação em Educação. E-mail: <ivonegbarbosa.ufg@gmail.com>.

** É Pedagoga, Mestre e Doutora em Educação pela Universidade Federal de Goiás. Atualmente é professora do Instituto Federal de Educação, Ciência e Tecnologia de Goiás. E-mail: <teles.telma@gmail.com>.

** Possui graduação em Licenciatura Plena em Educação Artística. É Mestre e Doutor em Educação pela Universidade Federal de Goiás. Atualmente é professor adjunto da Faculdade de Artes Visuais da Universidade Federal de Goiás. E-mail: <marcossoares.br@gmail.com>. 


\begin{abstract}
This article analyzes the constitution of the National Curricular Common Core (BNCC) in the Brazilian political, social and economic context and its impacts in the field of Early Childhood Education. Using the materialistic dialectic as a reference, through documentary analysis, we seek to highlight the guiding principles of the BNCC, which is articulated with a pragmatic conception of education linked to the neoliberal model. Emphasis is given to its contradictions and implications for Early Childhood Education.
\end{abstract}

Keywords: BNCC. Childhood education. Educational public policies.

RESUMEN: Este artículo analiza la constitución de la Base Nacional Común Curricular (BNCC) en el contexto político, social y económico brasileño y sus impactos en el campo de la educación infantil. Utilizando la dialéctica materialista como referencia a través del análisis documental, se busca demarcar los principios rectores de la BNCC, que se articulan con una concepción pragmática de la educación vinculada al modelo neoliberal, enfatizando sus contradicciones e implicaciones para la educación infantil.

Palabras clave: BNCC. Educación Infantil. Políticas públicas educativas.

\title{
Introdução
}

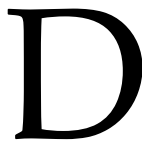

iante da aprovação e do movimento de "implementação" da Base Nacional Comum Curricular (BNCC) em todos os estados e municípios brasileiros, é necessário que aprofundemos a discussão sobre a sua trajetória e as implicações que dela decorrem para a educação infantil. A análise sobre a legislação educacional brasileira vigente permite-nos perceber que entre seus pressupostos encontra-se a proposta de constituição de uma base nacional comum. Esta, teoricamente, seria capaz de unificar os fins e princípios da educação básica, objetivando garantir acesso e permanência de todas as crianças, dos adolescentes, jovens e adultos, ao ensino de qualidade. Nesse sentido, cabe citar: a Constituição Federal - CF (BRASIL, 1988), a Lei de Diretrizes e Bases da Educação Nacional - LDB (BRASIL, 1996), as Diretrizes Curriculares Nacionais para a Educação Infantil - DCNEI (BRASIL, 2009), as Diretrizes Curriculares Nacionais Gerais para a Educação Básica - DCNEB (BRASIL, 2010) e o Plano Nacional de Educação - PNE (BRASIL, 2014). 
No ano de 2014, fortaleceu-se o debate sobre a construção de uma BNCC, modificando-se o conceito de base nacional comum, presente na legislação. Nesse contexto, nos diversos estados brasileiros, ocorreram manifestações e posicionamentos de especialistas, professores e gestores sobre a natureza e as funções históricas, sociais, político-ideológicas e educacionais da BNCC. Considerando esse movimento e os resultados da disputa de projetos que levou à configuração de uma BNCC segmentada, uma para a educação infantil e o ensino fundamental e outra para o ensino médio, o presente artigo analisa a BNCC da educação infantil, cuja proposta os autores rebateram criticamente em várias oportunidades em que discutiram publicamente todo o processo de elaboração da Base.

Optou-se por subdividir o artigo em duas seções inter-relacionadas, discutindo primeiramente o cenário e percurso político pelo qual se delineou a proposta de uma BNCC, enfatizando os diferentes projetos em disputa. Na segunda seção, apresentam-se análises críticas e considerações quanto ao conteúdo da BNCC para a educação infantil, sinalizando para suas contradições e consequências no debate sobre a formação de professores.

\section{BNCC e seu percurso: projetos em disputa}

Desde a promulgação da Constituição Federal de 1988, a legislação brasileira destacou entre suas premissas a elaboração de uma base acional comum somente para o ensino fundamental e médio. A Emenda Constitucional nº 59, de 2009, e, posteriormente, a LDB (BRASIL, 1996), alterada pela Lei 12.796 (BRASIL, 2013) incorporaram a educação infantil como uma das etapas educacionais obrigatórias. Nesta última aparece a proposta de base nacional comum conforme explícito no seguinte artigo:

Art. 26. Os currículos da educação infantil, do ensino fundamental e do ensino médio devem ter base nacional comum, a ser complementada, em cada sistema de ensino e em cada estabelecimento escolar, por uma parte diversificada, exigida pelas características regionais e locais da sociedade, da cultura, da economia e dos educandos (BRASIL, 2013).

Por que razão a base nacional comum se modifica para Base Nacional Comum Curricular? Nossa análise indica que a mudança nessa direção foi potencializada inicialmente pelos históricos e complexos debates entre os movimentos sociais, as entidades representativas dos diferentes segmentos sociais e o Ministério da Educação (MEC) sobre a melhoria da qualidade da educação. Cotejaram-se as temáticas: a existência de desigualdades regionais e entre classes sociais, a questão de recursos para os níveis, as etapas e modalidades da educação básica, assim como a redação das estratégias das metas 2, 3, 7, 15 do PNE (BRASIL, 2014) e a versão oficial para os resultados em avaliações internacionais.

Há de se considerar também nessa reflexão o contexto político-social e econômico brasileiro para entender de modo crítico os motivos pelos quais a implementação de 
uma BNCC se tornou pauta central do Governo brasileiro. Vale destacar, durante os anos de discussão pública da BNCC, a ocorrência de ampla rejeição dessa proposta por professores, pesquisadores e de entidades nacionais como Associação Nacional pela Formação de Profissionais da Educação (Anfope), Associação Nacional de Pós-Graduação (Anped), Associação Nacional de política e Administração da Educação (Anpae), Confederação Nacional dos Trabalhadores da Educação (CNTE), Grupo de Trabalho Educação de Crianças de 0 a 6 anos da Anped (GT7), Fórum Goiano de Educação Infantil (Fgoei), Núcleo de Estudos e Pesquisas da Infância e sua Educação em Diversos Contextos (Nepiec), entre outras.

Os acontecimentos que envolveram a Base abrangeram tantas ações políticas e econômicas do Governo Federal, de deputados e senadores, como reações da sociedade civil organizada. No período após o Golpe de Estado e midiático de 2016 - que levou ao impeachment da presidente Dilma Rousseff, eleita pela maioria da população - várias tentativas de impor medidas privatistas à educação em todos os níveis e de regular a ação educativa nas dimensões das macro e micro políticas foram explicitadas. Dentre elas podemos citar a proposta enviada ao Congresso Nacional em 2016, alterando o PNE, incluindo novo parágrafo para determinar que a BNCC, mediante proposta do Poder Executivo, fosse aprovada pelo Congresso Nacional e não pelo Conselho Nacional de Educação (CNE). Apesar daquele PL ter sido arquivado em 2019, e os privatistas que inspiravam o Congresso - denominados por Luiz Carlos Freitas (2014) de "reformadores empresariais da educação" - não poderem assumir a determinação e regulação da Base, esta acabou sendo definida por um novo CNE recomposto no período após o Golpe -, ocorrendo a destituição de vários membros que mantinham posição contrária às posições governamentais. Em substituição a estes, foram incorporados cinco novos membros alinhados com o Governo Temer, articulando-se interesses e propósitos do Movimento pela Base e o Todos pela Educação. Esses grupos assumiram a condução da educação nacional, retomando e atualizando, segundo Freitas (2018), a agenda do governo de Fernando Henrique Cardoso (FHC), a qual considera as exigências do movimento mundial pela reforma empresarial da educação, sempre incentivado pelas elaborações do Banco Mundial e outros organismos e agências internacionais (BARBOSA; MARQUEZ, 2007). Lembremos, ainda, que entre as motivações desse PL havia a posição de estratos conservadores contra o que chamaram de "ideologia de gênero" (incluindo a orientação sexual) nas escolas, assim como a imposição da educação religiosa na educação pública.

Em relação ao contexto em que a BNCC foi gestada e discutida, cabe mencionar a revogação da Portaria do MEC nº 369, de 5 de maio de 2016, que regulamentava o Sistema Nacional de Avaliação da Educação Básica (Sinaeb), estipulando-se a existência desse Sistema em caso de aprovação da BNCC. Essa medida tem relação com a desconstrução da Política Nacional de Educação Infantil e de Jovens e Adultos, traçando um caminho de controle gerencial da escola pública por meio da avaliação e determinações de interesse de um 
grupo social que possui o domínio do capital e a quem interessa historicamente manter a classe trabalhadora subjugada às regras do capitalismo excludente e baseado na desigualdade. Houve manifestações contrárias a essa revogação, de diferentes entidades - Anpae, Anped, Anfope, Rede da Campanha Nacional pelo Direito à Educação - considerada explícita ação do governo Temer com total descompromisso com a educação pública.

Para impedir a crítica ao sistema e à forma de estruturação social é que se entende a tentativa de impor aos atores da educação a "Lei da Mordaça" (como ficou conhecido o projeto da "Escola sem Partido") e os constantes ataques ideológicos à autonomia das universidades e dos professores de todos os níveis, etapas e modalidades da educação. Entende-se, nesse caso, a acirrada discussão em torno do Projeto de Lei nº 6.114, de 2009, do Senado Federal, que institui o Exame Nacional de Avaliação do Magistério da Educação Básica (Enameb/BRASIL, 2009), ironicamente apelidado na Câmara dos Deputados de “Enem dos Professores”, pelo qual se pretende avaliar as competências docentes e os domínios didático-pedagógicos de professores, incluindo a educação infantil. Outra medida que se alinhou àquelas já anunciadas foi o Projeto de Lei do Senado n⿳ำ116/2017, ainda em tramitação, que regulamenta o art. 41, §1 , III, da Constituição Federal (BRASIL, 1988), para dispor sobre a avaliação periódica dos servidores públicos da União, estados e municípios e a perda do cargo público por insuficiência de desempenho do servidor público estável.

Com o objetivo de manter o controle ideológico, foi apresentado pelo Ministério da Educação, em dezembro de 2018, o documento da Base Nacional Comum da Formação dos Professores da Educação Básica (BRASIL, 2018), o qual foi formulado sem qualquer diálogo com as instituições responsáveis pela formação dos professores, com as entidades, universidades, escolas e sindicatos, reiterando o caráter autoritário e arbitrário do atual contexto. A proposta desconsiderou completamente a existência das Diretrizes Curriculares Nacionais para a formação inicial em nível superior (cursos de licenciatura, cursos de formação pedagógica para graduados e cursos de segunda licenciatura) e para a formação continuada (BRASIL, 2015a; 2015b). Acrescenta-se àquelas medidas a proposição e implementação da "residência docente", integrando a política de formação de professores, cujo teor não se constituiu unanimidade entre as instituições formadoras e os professores.

Foi nesse contexto que em setembro de 2015 foi divulgada a versão preliminar da BNCC, elaborada por comissões de especialistas de cada área de conhecimento e da educação infantil, aberta à contribuição de professores/as, instituições educacionais, gestores/ as, grupos de pesquisa, associações científicas e movimentos sociais. Várias contribuições foram realizadas e encaminhadas, porém, não se pode garantir que de fato a nova versão tenha incorporado importantes contribuições de instituições públicas e privadas do País. No caso da educação infantil houve colaborações de diferentes grupos envolvidos com o campo, porém, o argumento apresentado pelas comissões organizadoras em relação aos cortes na redação foi de que o texto deveria ser de natureza operativa, não cabendo aprofundamentos teóricos e metodológicos. 
Em maio de 2016, lançou-se uma nova versão da BNCC com alterações significativas para a educação infantil. Para discutir o teor daquela criaram comitês estaduais da BNCC com diferentes participações, abarcando diferentes forças políticas, em sua maioria conservadora. Foram realizados seminários estaduais em todas as unidades da Federação. Neste período foi instituído o Comitê Gestor da Base Nacional Curricular Comum e Reforma do Ensino Médio (BRASIL, 2016). Contraditoriamente, essa medida significou a retirada do ensino médio da BNCC e a destituição dos especialistas envolvidos no processo de construção da BNCC até então. O MEC, contrariando todo o movimento de discussão, elaborou uma terceira versão e encaminhou ao CNE em abril de 2017. Ao longo daquele ano, esse conselho promoveu cinco audiências públicas regionais com o objetivo de colher sugestões, com caráter exclusivamente consultivo, não garantindo à sociedade civil que suas reivindicações seriam acolhidas. Apesar de um número expressivo de colaborações das entidades, o CNE não deu retorno sobre as proposições. No dia 15 de dezembro de 2017, a BNCC foi aprovada, com três votos contrários, publicando-se a Resolução CNE/CP no 2, de 22 de dezembro de 2017.

É preciso assinalar que o processo de proposição até a aprovação da BNCC abrangeu muitas tensões e questionamentos. As entidades organizadas e universidades, os movimentos sociais, os pesquisadores e professores se posicionaram contrários à metodologia pela qual ela foi construída, considerando o curto prazo para o aprofundamento dos debates acerca do seu conteúdo e suas consequências para o campo educacional, incluindo a formação de professores.

No teor do documento da BNCC (BRASIL, 2017) admite-se que ela não deve e não pode ser considerada como currículo. De acordo com o próprio texto, trata-se de documento orientador/referência para as instituições educacionais públicas e privadas. É necessário que se reconheça e garanta a autonomia dos entes federados e, sobretudo, das instituições educativas - contando com a efetiva e democrática participação de professores e outros trabalhadores da instituição, das famílias e crianças - na elaboração de seus currículos, como indica a LDB (BRASIL, 1996).

Porém, reagindo às críticas, ainda em 2018, o MEC criou o Programa de Implementação da Base Nacional Comum Curricular (ProBNCC), com o objetivo de apoiar cada unidade da federação (UF), por intermédio das Secretarias Estaduais e Distrital de Educação (SEDE) e das Secretarias Municipais de Educação (SME), no processo de revisão ou elaboração e implementação de seus currículos alinhados à BNCC, em regime de colaboração entre estados, Distrito Federal e municípios, contando com total apoio da União dos Dirigentes Municipais (Undime) e a dos Conselhos Municipais (Uncme).-

Assim, o que era para ser uma referência, passou a ser uma prescrição curricular tendente à homogeneização de conteúdos e organização da educação infantil no Brasil -, contrariando a autonomia garantida na LDB de 1996. O citado Programa prevê: apoio para a Elaboração e Revisão dos Currículos com repasse financeiro para elaboração ou 
revisão de currículos por estados e municípios; Plataforma de Construção de Currículos; Consultoria especializada para planejamento e implementação do processo de construção; Alinhamento das ações do MEC à BNCC, como Plano Nacional do Livro Didático, Mais Alfabetização, Guia de Tecnologia, Educação Conectada, Política Nacional de Formação, Plataforma Integrada, Avaliações, entre outras.

\section{A BNCC da educação infantil: análises e considerações sobre seu conteúdo}

Como analisamos anteriormente, a BNCC se constituiu devido a determinações legais e político-sociais, influindo na instituição de políticas públicas. Todo projeto curricular se dá em um movimento contraditório, envolvendo tensões, debates e embates de classes e grupos sociais em que se imiscuem questões políticas, ideológicas e pedagógicas. Percebe-se que nesse campo de disputas, a hegemonia dos ideários neoliberais, ancorada nas competências, ganhou espaço e lugar no campo da educação brasileira, sobretudo com as reformas do Estado e a reestruturação produtiva, que influenciaram, por sua vez, as reformas educacionais das décadas de 1990 e dos anos 2000. Essa luta de forças pode ser visualizada no processo de discussão sobre a BNCC da Educação Infantil, que em parte contribuiu para se conhecer diferentes concepções político-ideológicas demarcadas nas propostas concretas e discursivas daqueles que dela participaram.

Percebe-se que o debate sobre a BNCC acabou por privilegiar alguns grupos de especialistas, em detrimento da ampla sociedade organizada, desconhecendo acúmulos importantes de conhecimentos teórico-práticos produzidos por pesquisadores, professores, gestores e entidades sobre a questão curricular e os processos de aprendizagem e desenvolvimento. Foi visível a expectativa de participação de alguns grupos, entidades e indivíduos nas duas primeiras versões da BNCC e o sentimento de frustração destes, ao serem cerceados de opinar e transformar as duas últimas versões do documento. Esse sentimento parece que não alcançou aqueles que pensaram a Base Nacional Comum Curricular da Educação Infantil (BNCC-EI), à medida que alguns pesquisadores, professores e até parcelas de movimentos sociais encontraram semelhanças entre a segunda e quarta versões. Esta, porém, não é a posição que defendemos.

A análise detalhada da BNCC indica mudanças estruturais e de conteúdo, na definição dos direitos a serem garantidos a todas as crianças, adolescentes e jovens. Observa-se um esvanecimento quanto à formulação de direitos constitucionais, sendo retirados/omitidos pressupostos importantes na segunda, terceira e quarta versões no documento. Se o pressuposto de uma visão empresarial já estava anunciado desde a primeira versão, mantendo-se um campo de disputas políticas, a terceira e quarta versões da BNCC assumem como eixo a noção de competência, 
[...] utilizada no sentido da mobilização e aplicação dos conhecimentos escolares, entendidos de forma ampla (conceitos, procedimentos, valores e atitudes). Assim, ser competente significa ser capaz de, ao se defrontar com um problema, ativar e utilizar o conhecimento construído" (BARBOSA; SILVEIRA, 2017, p. 1).

Trata-se, pois, de uma visão instrumental, que serve para organizar não só o que a criança deverá aprender como também controlar o trabalho docente. Entende-se, desse modo, o aparecimento no documento da Base a identificação dos campos de experiência e objetivos de aprendizagem por um código alfanumérico, preparando os indicadores que servirão ao controle, abrangendo a condição de uma avaliação objetiva tanto da criança como de cada professor, delimitando o que se alcançou na aprendizagem individual e o que se deu conta de ensinar. Pode ser que isso favoreça o desaparecimento da avaliação de contexto, das interações entre as crianças e seus diferentes interlocutores.

Não é sem motivo, então, que se tem declarado que a proposta da BNCC mantém uma relação direta com as políticas de controle do Estado do campo educacional, por meio da avaliação das crianças desde a educação infantil, além da avaliação dos trabalhos dos professores por meio do Enameb. Nessa direção, a Base pressupõe uma visão de controle da formação e do trabalho dos professores e gestores, em que há uma visão de monitoramento das suas práticas pedagógicas; os seus fundamentos estão pautados em um viés pragmático, individual, segregador, distantes de uma visão pedagógica e política ampliadas. Essa compreensão, além de tirar a autonomia didático-pedagógica docente das instituições educacionais e da perspectiva crítica do processo de formação dos professores pela instituição de ensino superior, favorece o planejamento rígido, o apostilamento, com apoio em manuais e livros didáticos, muitos deles em versão ultrapassada e tradicional. Ademais, cabe ressaltar a existência da indústria cultural e a venda de materiais didáticos pré-concebidos, distribuídos/vendidos, sem crítica a todo esse processo de privatização do espaço público e a tomada da educação infantil como mercadoria por organizações sociais (OS) e outras incidências empresariais, ligadas à ideologia referendada pelo Banco Mundial.

A BNCC, nas terceira e quarta versões, não discute teoricamente suas premissas, alguns fundamentos e princípios, tratando objetivamente de "direitos de aprendizagem", interpretando os direitos, portanto, de modo sistêmico, relacionando-os ao ambiente de escolarização. É mister afirmar que já na terceira versão havia uma perda enorme na discussão de princípios e de premissas que valorizassem a criança e seus direitos, para sustentar a discussão dos campos de experiência e objetivos de aprendizagem. Os "direitos" de aprendizagem direcionam o enfoque das políticas educacionais para dentro da escola e o trabalho do professor.

Sem negar a importância da escola, é preciso atentar para o significado da educação de caráter humanizador que, na contemporaneidade, não prescinde da escola, mas que, também, não pode se resumir a ela - entendendo-se a educação como uma prática social ampla e multifacética (BARBOSA; SOARES, 2018). Como mostraram Vygotsky 
(2001), Wallon (1975), a aprendizagem não está restrita à etapa escolar, apesar de a escola introduzir algo completamente novo na vida da criança, favorecendo a apropriação de novos conhecimentos e o seu desenvolvimento.

Nessa perspectiva, podemos afirmar que a aprendizagem não é um ato puramente individual e que os processos de ensino-aprendizado e desenvolvimento se constituem de modo articulado e são pressupostos e partes integrantes das práticas educativas. Como afirmou Barbosa (2015), ela é sempre um processo compartilhado, ou seja, simultaneamente processo e resultado de atividades e ações individuais e partilhadas com outros. Assim, consideramos positiva a incorporação da noção de "aprendizagens", em substituição à "aprendizagem", conforme sugestão do documento do Fgei-GO (GOIÁS, 2016) na segunda versão, assim como nas demais.

Cabe ainda evidenciar outros aspectos que surgiram a partir da segunda versão da BNCC e que envolvem não apenas uma transformação na "forma" de organização didática, mas na concepção sobre a criança e a função social e política da educação da infância em espaços institucionais. A noção de aprendizagens partilhadas dialeticamente entre criança e seus meios e grupos (WALLON, 1975) leva à necessidade de superação do conceito de currículo como simples lista de objetivos e de conteúdos mínimos, concebidos como algo neutro e universal, escolhido por professores e especialistas de modo "desinteressado". Trata-se de uma versão que, de um lado, delega às instituições, ou melhor, aos gestores e professores a determinação de todo conhecimento a ser posto à disposição das crianças. Por outro lado, de modo contraditório, acredita-se que estas tendem a "assimilar naturalmente" o que está indicado ou aparentemente potencializado na ação que a própria criança desenvolve, sendo considerada agente de seu próprio desenvolvimento.

É preciso considerar que a formação do indivíduo se constitui dialeticamente em diferentes dimensões: humana, social, cultural, política e, necessariamente, num ambiente democrático. Reconhecemos que as crianças e suas famílias devem ser assumidas como interlocutoras e protagonistas, por direito, da organização do trabalho pedagógico, assim como os professores e gestores. O direito à participação e à forma de tratamento do conhecimento a ser disponibilizado no ambiente das creches e pré-escolas, parece não estar citado em todas as suas dimensões, sobretudo quando os direitos sociais são retirados dos fundamentos da BNCC, comojá aludimos anteriormente. Eles foram substituídos por "direitos de aprendizagem", que não são equivalentes aos direitos sociais, como o direito à vida digna, à saúde, à moradia, à boa alimentação, por exemplo.

Esses direitos fogem à lógica da divisão e sequenciação do projeto educativo por idades, a que se resumiu o texto da BNCC-EI ao tratar dos objetivos de aprendizagem, evocando, igualmente, as questões ontológicas, históricas, de classe social e das relações dela decorrentes, da cultura, das relações étnico-raciais, além das conquistas e dos processos de ordem biológica e filogenéticos. Além disso, o fato de destituir as crianças de menos idade, do nascimento aos 18 meses, do estatuto de "criança", classificando-as 
como "bebês", não tem uma justificativa epistemológica plausível, podendo essa divisão favorecer uma discriminação no atendimento daquelas, a ponto de, ao invés de tratá-las com o devido cuidado, interpretá-las como ser com menor capacidade ou menos ativos, o que não é absolutamente verdade. Denominar crianças de 19 meses a 3 anos e 11 meses como "mais pequenas" e as de 4 anos a 5 anos e 11 meses de "pequenas", não corresponde ao que elas de fato são, já que não podem ser analisadas pelo tamanho, em escala. Além disso, as crianças de seis anos ficaram de fora dessa classificação. O que seriam elas, "crianças grandes"? O grande risco político aqui é o retrocesso de nossas lutas pelo atendimento de todas as crianças de zero até seis anos em instituições integradas, em tempo integral, assumidas pelos sistemas educacionais e não mais pela assistência social apenas, assumindo o direito a ter professores com formação teórica sólida e consciente das funções sócio-históricas da escola e outras instituições educativas.

Outro ponto também nos chama a atenção. Ao tratar os conhecimentos, as habilidades e as necessidades de um modo segmentado, a BNCC da Educação Infantil se aproxima de uma espécie de seriação e hierarquização dos conteúdos e atividades a serem propostos no trabalho docente com as crianças. Do modo como se apresenta, a ideia de currículo reforça a ideia de currículo como "conjunto de práticas" ou, ainda, como rol de atividades sequenciais, pelas quais se procederá à avaliação dos níveis de desenvolvimento infantil. Em visita a um Centro Municipal de Educação Infantil de uma cidade brasileira uma das professoras nos declarou: "gostava mais quando era mais livre, sem ser em sequência...". Pensamos, pois, que qualquer desenho curricular deveria ser compreendido de modo mais amplo (BARBOSA, ALVES, 2016).

Dessa ótica, preocupa-nos a forma como a descrição dos objetivos de aprendizagem aparecem na BNCC em sua terceira e última versão. Uma leitura desatenta pode levar professores e professoras a interpretarem que a forma gradativa em que certos objetivos (como os que se referem à linguagem, por exemplo) aparecem seria indicador da pré-escola como etapa preparatória para os objetivos da primeira etapa do ensino fundamental. Há fortes indícios de que a lógica das competências, na qual a BNCC foi proposta e organizada, conduz a uma aproximação da proposta para a educação de crianças de zero até cinco anos com a lógica assumida pelo ensino fundamental, que aparece segmentado em primeira e segunda etapa. Além disso, conduz para uma discriminação das crianças de até um ano e seis meses e ao esquecimento das crianças de seis anos, que ainda permanecem na educação infantil, respeitando a data de corte etário conforme indicação do CNE. Essa forma de sequenciar as etapas pode conduzir a uma perda da noção de totalidade do processo, sequenciando-se o conhecimento de modo cartesiano, induzindo à noção de que na creche se pode aceitar leigos no lugar dos professores e que a formação ao nível do ensino superior é desnecessária, mantendo-se, ademais, a formação continuada como apenas atualização pragmática, centrada no "como fazer", isto é, em uma ótica puramente instrumental. 


\section{Considerações finais}

Vislumbramos em nossas análises o contexto das políticas públicas educacionais para a educação infantil e a necessidade premente de ações necessárias na garantia da qualidade da educação brasileira, dentre as quais entendemos a urgente garantia de formação inicial e continuada para professores (as) que atuam na primeira etapa da educação básica. O processo de elaboração e aprovação da BNCC em 2017, suscitou importantes discussões, debates e críticas. Nesse processo, considerando o acúmulo de estudos, experiências e avanços do campo da educação infantil e da formação de professores nas últimas décadas, evidenciamos que aspectos importantes já formulados na área por diferentes pesquisadores, especialistas, movimentos sociais e entidades acadêmico-científicas não se consubstanciaram na BNCC-EI. Ao invés disso, essa tem assumido como perspectiva a padronização e o alinhamento das práticas, exigindo o mesmo da formação inicial e continuada de professores. Na proposição do documento, caracteriza-se uma forma de controle do trabalho educativo, dando espaço para uma possível proposição de testes e medidas de larga escala para medir as capacidades infantis, servindo, nesse caso para opressão e exclusão das crianças e suas famílias, sobretudo as de baixa renda. Ao verticalizar a ideia de aprendizagem sobre a criança, vislumbrando o trabalho docente destituído de crítica e de criação, os processos de aprendizagem acabaram relegando a segundo plano as condições estruturais, de materiais adequados e valorização profissional, elementos necessários àquilo que se faz importante no processo educacional. Evidencia-se que, aos poucos, com a divisão rígida das idades podendo fortalecer o biologicismo na educação infantil, retorna ao cenário educativo a ideia de etapas de aprendizagem e de desenvolvimento, promovendo-se a sequenciação de conteúdos/ objetivos, tudo isso revestido com uma perspectiva próxima ao escolanovismo, mas com tradução em uma realidade em que há aumento da pobreza, do trabalho infantil, dos ataques à democracia, da retirada aos bens sociais e recrudescimento da violência pouco enfatizada nos campos de experiência e objetivos de aprendizagem.

Destacamos nesse texto a necessidade de construção e efetivação de um projeto humanizador, justo e democrático que vai à contramão da lógica neoliberal impetrada na política educacional do Brasil, a qual tem acentuado as desigualdades sociais em nosso país. Defendemos um projeto de educação para as crianças de zero até seis anos de idade com professores formados em nível da educação superior, que trabalhe de forma integrada, sem cindir a creche e a pré-escola, idealizando a oferta em centros integrados e em tempo integral, a fim de garantir o direito a uma condição de convivência e baseada em direitos plenos da infância cidadã, conforme determina a Constituição Federal (BRASIL, 1988), pela qual muitos de nós lutamos.

Reconhecemos, respeitosamente, a qualidade da escrita da proposta da educação infantil, da seriedade pela qual a equipe de especialistas se dedicou a ela na versão 
preliminar, e, ainda, sua diferença qualitativa do restante do documento da BNCC. Entretanto, o fato de a Base se submeter ao conceito de competência e meritocracia na perspectiva neoliberal permite questionar seu valor histórico para a construção de uma educação infantil de qualidade na esfera dos direitos sociais da maioria da população. Reafirmamos aqui que as DCNEI para a Educação Infantil (BRASIL, 2009) se mostram, nesse sentido, mais avançadas do que a BNCC-EI e devem ser elas as referências para pensarmos amplamente os direitos das crianças de zero até seis anos a uma educação de qualidade, sem homogeneizar as propostas curriculares nas diferentes instâncias do nosso país, recorrendo à ameaça de liberação dos recursos a que todo o povo brasileiro tem direito de usufruir.

Recebido em: 04/06/2019 e aprovado em: 17/06/2019

\section{Referências}

BARBOSA, I. G. Base Nacional Comum Curricular: pressupostos e implicações para o trabalho docente. Goiânia, 2015 (impresso).

BARBOSA, I. G.; ALVES, N. N. L. Currículo da Educação Infantil e trabalho docente. In: SOUZA, R. C. C. R. (Org.). Formação, profissionalização e trabalho docente: em defesa da qualidade social da educação. Campinas, SP: Mercado de Letras, 2016, p. 201-222.

BARBOSA, I. G.; SILVEIRA, T. A. T. M. Posicionamento do Núcleo de Estudos e Pesquisas da Infância e sua educação em diferentes contextos (NEPIEC/ FE/UFG) sobre a $3^{\text {a }}$ versão da BNCC. Goiânia: impresso, 2017.

BARBOSA, I. G.; SOARES, M. A. Educação estética na perspectiva histórico-cultural: contribuições à educação infantil de orientação dialética. In: Educar na perspectiva histórico-cultural: diálogos vigotskianos. Campinas, SP: Mercado de Letras, 2018, p. 137-160.

BARBOSA, I. G.; GARRIDO, C. M. A educação infantil brasileira e as políticas setoriais de educação do Banco Mundial. In: II ENDIPE, Anápolis. Anais. Goiás, 2007. Disponível em: < http://www.ceped.ueg. br/anais/IIedipe/pdfs/a_educacao_infantil_bras_.pdf >>. Acesso em: 19 jul. 2016.

BRASIL. Constituição da República Federativa do Brasil de 1988. Diário Oficial da União, Brasília, v. 126, n. 191, 5 out. 1988. Seção 1.

BRASIL. Projeto de Lei no 6.114, de 2009. Institui o Exame Nacional de Avaliação do Magistério da Educação Básica - Enameb. Disponível em: https://www.camara.leg.br/proposicoesWeb/prop_mostrar integra;jsessionid=848214BAAC04FBA3EF3764E9AED28213. proposicoesWeb2? codteor=1348646\&filena me=Avulso+-PL+6114/2009 . Acesso em: 02 de junho de 2019.

BRASIL/MEC/ CNE/CEB. Institui as Diretrizes Curriculares Nacionais Para a Educação Infantil. Resolução CNE/CEB 5/2009. Diário Oficial da União, Brasília, 18 de dezembro de 2009. 
BRASIL. Resolução CNE/CEB no 4/2010. Define Diretrizes Curriculares Nacionais Gerais para a Educação Básica. Diário Oficial da União, Brasília, 14 de julho de 2010.

BRASIL. Lei n. 9.394. Estabelece as Diretrizes e Bases da Educação Nacional. Diário Oficial da União, Brasília, 20 de dezembro de 1996.

BRASIL. Lei no 13.005, de 25 de junho de 2014. Aprova o Plano Nacional de Educação - PNE e dá outras providências. Diário Oficial da União, Brasília, DF, 26 jun. 2014.

BRASIL. MEC. Parecer CNE/CP no 2/2015. Diretrizes Curriculares Nacionais para a Formação Inicial e Continuada dos Profissionais do Magistério da Educação Básica. Diário Oficial da União, Brasília, DF, 25 jun. 2015a. Seção 1, p. 13.

BRASIL. Ministério da Educação (MEC). Resolução CNE/CP no 2, de 10 de julho de 2015. Define as Diretrizes Curriculares Nacionais para a formação inicial em nível superior (cursos de licenciatura, cursos de formação pedagógica para graduados e cursos de segunda licenciatura) e para a formação continuada. Diário Oficial da União, Brasília, 25 jun. 2015b. Seção 1, p. 8-12.

BRASIL. MEC. Portaria № 790, de 27 de julho de 2016 que instituiu o Comitê Gestor da Base Nacional Curricular Comum e reforma do Ensino Médio. Brasília, 2016.

BRASIL. MEC. Portaria no 369 de 5 de maio de 2016. Institui o Sistema Nacional de Avaliação da Educação Básica - Sinaeb. Diário Oficial da União, Brasília, 06 de maio de 2016.

BRASIL. MEC. Portaria no 790, de 27 de julho de 2016. Institui o Comitê Gestor da Base Nacional Curricular Comum e reforma do Ensino Médio. Diário Oficial da União, Brasília, 28 de julho de 2016.

BRASIL/MEC. Base Nacional Comum da Formação dos Professores da Educação

Básica. Brasília, 2018. Disponível em: http://portal.mec.gov.br/index.php?option=com_docman\& view=download\&alias=105091-bnc-formacao-de-professores-v0\&category_slug=dezembro-2018pdf\&Itemid=30192. Acesso em: 04 de junho de 2019.

BRASIL. MEC. CNE/CP. Resolução CNE/CP nº 2/2017. Institui e orienta a implantação da Base Nacional comum curricular, a ser respeitada obrigatoriamente ao longo das etapas e respectivas modalidades no âmbito da Educação Básica. Diário Oficial da União, Brasília, 22 de dezembro de 2017.

BRASIL. Lei no 13.145, de 16 de fevereiro de 2017. Altera a Leis no 9.394, de 20 de dezembro de 1996, que estabelece as diretrizes e bases da educação nacional. Disponível em : <http://www.planalto.gov. br/ccivil_03/_ato2015-2018/2017/lei/113415. htm>. Acesso em: 17 de maio de 2019.

BRASIL/MEC/ CNE/CEB. Resolução CNE/CEB 2/2018. Diretrizes Operacionais complementares para a matrícula inicial de crianças na Educação Infantil e no Ensino Fundamental, respectivamente, aos quatro e aos seis anos de idade. Diário Oficial da União, Brasília, 10 de outubro de 2018, Seção 1, p. 10

BRASIL. MEC. Portaria 331, 05 de abril de 2018. Programa de Implementação da Base Nacional Comum Curricular - ProBNCC. Diário Oficial da União, Brasília, 06 de abril de 2018

FREITAS, L. C. Os reformadores empresariais da educação e a disputa pelo controle do processo pedagógico na escola. Educação e Sociedade, Campinas, CEDES, v. 35, n. 129, p. 1085-1114, dez. 2014.

FREITAS, L. C. Dia D da BNCC: 12 razões para não ser coadjuvante. In: Avaliação Educacional - Blog do Freitas. Publicado em 05/03/2018. 
GOIÁS. Parecer do Grupo de Trabalho de Educação Infantil do Estado de Goiás (GTEI-GO) ao documento da Base Nacional Comum Curricular (BNCC) - segunda versão. 2016. Disponível em: http://www.nepiec.com.br/BNCCEI\%20VERS\%C3\%83O\%20FINAL\%20GT\%20EI\%20\%20enviado.pdf. Acesso em agosto de 2016.

VIGOTSKI, L. S. Psicologia Pedagógica. São Paulo: Martins Fontes, 2001.

WALLON, H. Psicologia e educação da infância. Lisboa: Estampa, 1975. 